Wang Fang* and Chen Yigang

\title{
Crystal structure of sodium caesium zinc phosphate, $\mathrm{NaCsZnP}_{2} \mathrm{O}_{7}$
}

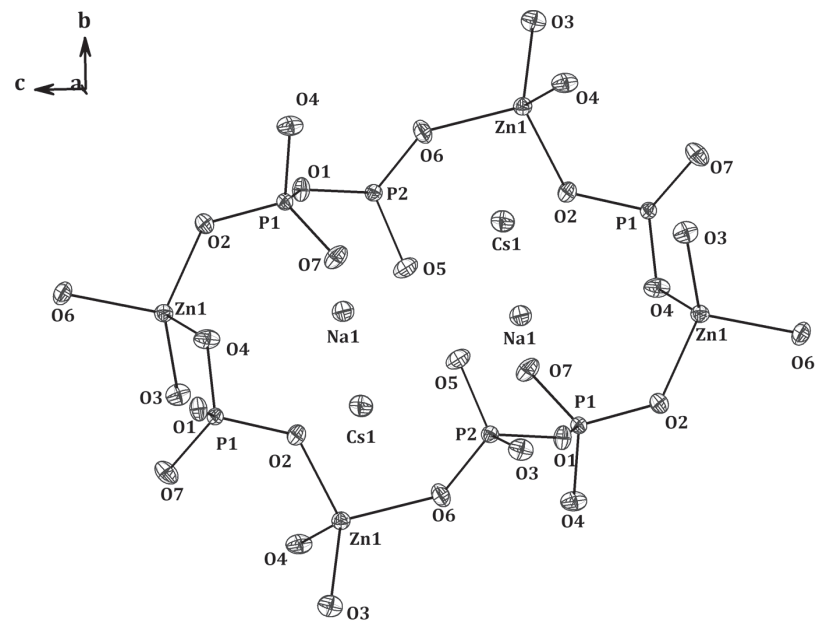

https://doi.org/10.1515/ncrs-2018-0101

Received June 10, 2018; accepted August 9, 2018; available online October 11, 2018

\section{Abstract \\ NaCsZnP $\mathrm{O}_{7}$, monoclinic, $P 2_{1} / n$ (no. 14), $a=7.3873$ (3) A,, $b=7.6637(2) \AA ̊ \quad \quad c=12.9658(4) \AA, \quad \beta=91.249(3)^{\circ}$, $V=733.87(4) \AA^{3}, Z=4, R_{\mathrm{gt}}(F)=0.0221, w R_{\text {ref }}\left(F^{2}\right)=0.0569$, $T=293(2) \mathrm{K}$.}

\section{CCDC no.: 1861154}

The crystal structure is shown in the figure. Tables 1 and 2 contain details on crystal structure and measurement conditions and a list of the atoms including atomic coordinates and displacement parameters.

\section{Source of material}

All reagents and solvents employed were commercially available and used as received without further purification.

\section{Experimental details}

The raw materials $\mathrm{Na}_{2} \mathrm{CO}_{3}(1 \mathrm{mmol}, 0.107 \mathrm{~g}), \mathrm{NaF}(1 \mathrm{mmol}$, $0.042 \mathrm{~g}$ ), $\mathrm{ZnO}$ (2 mmol, $0.163 \mathrm{~g}$ ), $\mathrm{NH}_{4} \mathrm{H}_{2} \mathrm{PO}_{4}$ (8 mmol, $0.92 \mathrm{~g}$ ),

\footnotetext{
*Corresponding author: Wang Fang, Department of Chemistry and Environmental Engineering, Anyang Institute of Technology, Anyang 455000, Henan, P.R. China, e-mail: wfayit@163.com Chen Yigang: School of Chemistry and Material Science, Shanxi Normal University, Linfen 041004, Shanxi, P.R. China
}

Table 1: Data collection and handling.

\begin{tabular}{ll}
\hline Crystal: & Block, colorless \\
Size: & $0.25 \times 0.15 \times 0.10 \mathrm{~mm}$ \\
Wavelength: & Mo $K \alpha$ radiation $(\lambda=0.71073 \AA)$ \\
$\mu:$ & $8.723 \mathrm{~mm}^{-1}$ \\
Diffractometer, scan mode: & Multiwire proportional, $\Phi$ and \\
& $\omega$-scans \\
$\theta_{\text {max }}$, completeness: & $26.4^{\circ}, 100 \%$ \\
$N(h k l)_{\text {measured }}, N(h k l)_{\text {unique }}, R_{\text {int }}:$ & $5402,1505,0.0334$ \\
Criterion for $I_{\text {obs }}, N(h k l)_{\text {gt }}:$ & $I_{\text {obs }}>2 \sigma\left(I_{\text {obs }}\right), 1398$ \\
$N(\text { param })_{\text {refined }}:$ & 110 \\
Programs: & CrysAlis \\
& OLEX2 [4] $[1]$, SHELX $[2,3]$, \\
\hline
\end{tabular}

Table 2: Fractional atomic coordinates and isotropic or equivalent isotropic displacement parameters $\left(\AA^{2}\right)$.

\begin{tabular}{lrrrr}
\hline Atom & $\boldsymbol{x}$ & $\boldsymbol{y}$ & $\boldsymbol{z}$ & $\boldsymbol{U}_{\text {iso }} / \boldsymbol{U}_{\text {eq }}$ \\
\hline Cs1 & $0.09609(3)$ & $0.78029(3)$ & $0.89360(2)$ & $0.02010(14)$ \\
Zn1 & $-0.15993(6)$ & $1.01716(5)$ & $0.62474(3)$ & $0.01113(15)$ \\
P1 & $0.03416(13)$ & $0.72499(11)$ & $1.20409(8)$ & $0.0095(2)$ \\
P2 & $0.18158(13)$ & $0.78392(11)$ & $0.58893(8)$ & $0.0099(2)$ \\
Na1 & $-0.1172(2)$ & $0.5184(2)$ & $0.61397(12)$ & $0.0157(3)$ \\
O1 & $0.3186(3)$ & $0.7985(3)$ & $0.6872(2)$ & $0.0134(6)$ \\
O2 & $0.0490(4)$ & $0.7733(3)$ & $1.3182(2)$ & $0.0159(6)$ \\
03 & $-0.0013(4)$ & $0.8177(3)$ & $0.6378(2)$ & $0.0159(6)$ \\
04 & $0.1139(4)$ & $0.5421(3)$ & $1.1921(2)$ & $0.0165(6)$ \\
05 & $0.1871(4)$ & $0.6034(3)$ & $0.5457(2)$ & $0.0187(6)$ \\
06 & $0.2376(4)$ & $0.9286(3)$ & $0.5156(2)$ & $0.0177(6)$ \\
07 & $0.1031(3)$ & $0.8584(3)$ & $1.1313(2)$ & $0.0172(6)$ \\
\hline
\end{tabular}

and $\mathrm{Cs}_{2} \mathrm{CO}_{3}$ ( $3 \mathrm{mmol}, 0.978 \mathrm{~g}$ ), were ground in an agate mortar, pressed into a pellet, placed in a Pt crucible and preheated in a muffle furnace at $723 \mathrm{~K}$ for $12 \mathrm{~h}$ to eliminate the water and gas. And then, it was reground thoroughly, placed in a Pt crucible and heated at $1073 \mathrm{~K}$ for $38 \mathrm{~h}$ to homogenize the solution, then cooled to $1023 \mathrm{~K}$ at a rate of $30 \mathrm{~K} \cdot \mathrm{h}^{-1}$, and slowly cooled to $773 \mathrm{~K}$ at a rate of $2 \mathrm{~K} \cdot \mathrm{h}^{-1}$ before the furnace was turned off. Colorless and block crystals were obtained.

\section{Discussion}

Phosphate crystals have garnered the wide attention attributed to some important applications like laser hosts, phosphors, electrode materials, birefringent optics and 
nonlinear optical materials [5-8]. Distinct from structural diversity of borates [9-13], phosphates only possessing the $\mathrm{PO}_{4}$ strict tetrahedron are more likely to produce orderly arrangements such as infinite chain, ring, and isolated clusters [14]. However, combination of the $\mathrm{PO}_{4}$ and $\mathrm{ZnO}_{4}$ tetrahedra has been investigated relatively less. Thus, synthesis of new zinc phosphate compounds are instructive to crystal chemistry and materials science.

The new compound NaCsZnP $\mathrm{O}_{7}$ crystallizes in a monoclinic crystal system with the space group $P 2_{1} / c$. Its asymmetric unit is composed of one crystallographically independent $\mathrm{Cs}$ atom, one $\mathrm{Na}$ atom, one $\mathrm{Zn}$ atom, two $\mathrm{P}$ atoms, and seven $\mathrm{O}$ atoms. Each $\mathrm{P}$ or $\mathrm{Zn}$ atom is linked to four $\mathrm{O}$ atoms to form $\mathrm{PO}_{4}$ or $\mathrm{ZnO}_{4}$ tetrahedra with $\mathrm{P}-\mathrm{O}$ or $\mathrm{Zn}-\mathrm{O}$ bond lengths varying from $1.4894(26)$ to $1.5232(26) \AA$ or 1.9309 (26) to $1.9423(26) \AA$. The bond lengths are close to those reported in the literature [14-16]. Viewing down the $a$ axis, the three-dimensional structure is built up of $\left[\mathrm{Zn}_{4} \mathrm{P}_{6} \mathrm{O}_{30}\right]^{22-}$ ten-membered rings obtained from the alternate linkages of $\mathrm{P}_{2} \mathrm{O}_{7}, \mathrm{ZnO}_{4}$, and $\mathrm{PO}_{4}$ groups. And the large rings via O-sharing stack along the $a$-axis direction to produce the large channels. The Cs and $\mathrm{Na}$ cations reside in the channels and maintain the charge balance.

Acknowledgements: This work was supported by the National Natural Science Foundation of China (Grant No. 21302003).

\section{References}

1. Agilent Technologies: CrysAlis ${ }^{\text {PRO }}$ Software system, version 1.171.39.27b, Agilent Technologies UK Ltd, Oxford, UK (2015).

2. Sheldrick, G. M.: SHELXL-97: program for the refinement of crystal structures. University of Gottingen, Germany (1997).

3. Sheldrick, G. M.: Crystal structure refinement with SHELXL. Acta Crystallogr. C71 (2015) 3-8.

4. Dolomanov, O. V.; Bourhis, L. J.; Gildea, R. J.; Howard, J. A. K.; Puschmann, H.: OLEX2: a complete structure solution, refinement and analysis program. J. Appl. Crystallogr. 42 (2009) 339-341.
5. Bruce, D. W.; O'Hare, D.; Walton, R. I., Eds.: Functional oxides. Wiley: Chichester, UK (2010).

6. Huang, H. W.; Liu, L. J.; Jin, S. F.; Yao, W. J.; Zhang, Y. H.; Chen, C. T.: Deep-ultraviolet nonlinear optical materials: $\mathrm{Na}_{2} \mathrm{Be}_{4} \mathrm{~B}_{4} \mathrm{O}_{11}$ and $\mathrm{LiNa}_{5} \mathrm{Be}_{12} \mathrm{~B}_{12} \mathrm{O}_{33}$. J. Am. Chem. Soc. 135 (2013) 18319-18322.

7. Xu, Y. M.; Richard, P.; Nakayama, K.; Kawahara, T.; Sekiba, Y.; Qian, T.; Neupane, M.; Souma, S.; Sato, T.; Takahashi, T.; Luo, H.-Q.; Wen, H.-H.; Chen, G.-F.; Wang, N.-L.; Wang, Z.; Fang, Z.; Dai, X.; Ding, H.: Fermi surface dichotomy of the superconducting gap and pseudogap in underdoped pnictides. Nat. Commun. 2 (2011) 394.

8. Chen, Y. G.; Xing, M. L.; Liu, P. F.; Guo, Y.; Yang, N.; Zhang, X. M.: Two phosphates: noncentrosymmetric $\mathrm{Cs}_{6} \mathrm{Mg}_{6}\left(\mathrm{PO}_{3}\right)_{18}$ and centrosymmetric $\mathrm{Cs}_{2} \mathrm{MgZn}_{2}\left(\mathrm{P}_{2} \mathrm{O}_{7}\right)_{2}$. Inorg. Chem. 56 (2017) 845-851.

9. Wang, Y.; Pan, S. L.: Recent development of metal borate halides: crystal chemistry and application in second-order NLO materials. Coord. Chem. Rev. 323 (2016) 15-35.

10. Yao, W. J.; Jiang, X. X.; Huang, H. W.; Xu, T.; Wang, X. S.; Lin, Z. S.; Chen, C. T.: $\mathrm{Sr}_{8} \mathrm{MgBr}_{18} \mathrm{O}_{36}$ : a new alkaline-earth borate with a novel zero-dimensional $\left(\mathrm{B}_{18} \mathrm{O}_{36}\right)^{18-}$ anion ring. Inorg. Chem. 52 (2013) 8291-8293.

11. Ju, J.; Lin, J. H.; Li, G. B.; Yang, T.; Li, H. M.; Liao, F. H.; Loong, C. K.; You, L. P.: Aluminoborate-based molecular sieves with 18 -octahedral-atom tunnels. Angew. Chem. Int. Ed. 42 (2003) 5607-5610.

12. Attfield, J. P.; Bell, A. M. T.; Rodriguez-Marti-nez, L. M.; Greneche, J. M.; Cernik, R. J.; Clarke, J. F.; Perkins, D. A.: Electrostatically driven charge-ordering in $\mathrm{Fe}_{2} \mathrm{OBO}_{3}$. Nature 396 (1998) 655-658.

13. Chuangtian, C.; Bochang, W.; Aidong, J.: A new type ultraviolet SHG crystal: /b- $\mathrm{BaB}_{2} \mathrm{O}_{4}$. Sci. Sin. Ser. B 28 (1985) 235-243.

14. Kim, S. C.; Lee, M. S.; Kang, J.; Kim, Y. I.; Kim, S. J.: Crystal structure and ion conductivity of a new mixed-anion phosphate $\mathrm{LiMg}_{3}\left(\mathrm{PO}_{4}\right) \mathrm{P}_{2} \mathrm{O}_{7}$. J. Solid State Chem. 225 (2015) 335-339.

15. Yu, H. W.; Zhang, W. G.; Yong, J. S.; Rondinelli, J. M.; Halasyamani, P. S.: Design and synthesis of the berylliumfree deep-ultraviolet nonlinear optical material $\mathrm{Ba}_{3}\left(\mathrm{ZnB}_{5} \mathrm{O}_{10}\right)$ $\mathrm{PO}_{4}$. Adv. Mater. 27 (2015) 7380-7385.

16. Orliukas, A. F.; Venckute, V.; Daugela, S.; Kezionis, A.; Dindune, A.; Valdniece, D.; Ronis, J.; Lelis, M.; Mosialek, M.; Salkus, T.: Synthesis, structure and impedance spectroscopy of $\mathrm{NaCsZn}_{0.5} \mathrm{Mn}_{0.5} \mathrm{P}_{2} \mathrm{O}_{7}$ pyrophosphate ceramics. Solid State Ionics 302 (2017) 92-97. 